\title{
PSYCHIATRIC BATTLE CASUALTIES FROM A BIOLOGICAL VIEWPOINT
}

\author{
Colonel T. B. STEPHENS, \\ M.B., F.R.C.P.E., F.R.C.Psych., Late R.A.M.C. \\ Royal Victoria Hospital, Netley
}

UNTIL recent years casualties of war have not been unique but they are now tending to be of a special kind not common in peacetime. This tendency is especially marked with psychiatric reactions, like battle exhaustion, which occur in considerable numbers during major conflicts but almost never at other times. As a result, those of us who have had the good fortune not to have seen such cases, when we need to know about them must have recourse to elderly pamphlets, books or films which were produced in a different idiom and in ignorance of present day knowledge and attitudes. This essay is meant to provoke interest and comment especially among those who have seen such casualties and who may or may not agree with the attempt to fit the recorded war-time experience to more modern scientific work.

In a future war psychiatric casualties in major disaster situations could well assume enormous importance because of numbers and because their prompt recovery in chaotic conditions could provide large reinforcements of fit troops while their mis-management could lead to an overwhelming burden on the medical services as well as a heavy drain on manpower. It is often assumed, naively, that this sort of thing could be stopped by efficient selection but it has never yet proved possible to eliminate psychiatric casualties and, indeed, it is unlikely ever to be so. Certain dimensions of mind, like intelligence, can be measured with reasonable accuracy but selection to withstand battle stress is a different matter involving attempts to measure reaction tendencies to stresses which are not available before the event; for example, during World War II, two per cent of all men medically examined for military service in the United Kingdom were rejected on psychiatric grounds yet 31 per cent of medical discharges were on psychiatric grounds (Belas 1973). Indeed the corresponding American figures were even higher at 10 per cent and 45 per cent respectively (Ahrenfeldt 1968). Nor is it possible to make psychiatric casualties disappear by rejection or denigration. Such behaviour only adds to the stress on them. They must be understood, not in order that they may be forgiven, but in order that they may be competently handled.

Superficially, the causation of psychiatric casualties is simple: Stress. But stress is not something which can be measured in isolation in psychology any more than it can be in physics. We must take account of the stressee as well as the stressor. For example an intelligent man may be more stressed by unpleasant anticipation of some imagined prospect which has no current influence on his comfort whereas a stupid one, unable to imagine it effectively, can dismiss it, while, on the other hand, a simple problem solved by the first without thinking about it may be intolerable to the second. For this reason it is nonsense to talk about the stressful pace of modern life without taking into account the training and responses of modern man. In battle casualties it is obvious that the principal stresses will be those of war viz. fear, deprivation and the infliction of discomfort by noise, injuries, disease and physical and mental discomfort. Belas, discussing battle exhaustion, which he describes as "one of the unique phenomena of battle" 
says that " men are especially sensitive to battle stress where exposure is prolonged or is repeated and the effects appear to be cumulative. In the light of experience it is certain that modern mechanised warfare imposes on the individual a strain so great that those involved in actual fighting, however basically stable they may be, will ultimately break down in direct proportion to the intensity and duration of their exposure to the stress of battle" (Belas 1973). However, in any group there must always be other factors to be considered, for example, victory, purpose, religion, morale etc. and, there will be individual factors such as early social training, security of home, motivation, attitudes to authority and physical status at the crucial time.

These factors are inter-related. For example, a group under stress but tolerating it may be precipitated into decompensation by the existence of one member who is more vulnerable than the rest but whose visible breakdown infects others who had previously managed to retain control.

The actual mechanisms of mental breakdown under stress are not readily understood because, though we understand the working of the brain and the human organism with considerable accuracy at the molecular, cellular and reflex levels, as complexity increases it becomes necessary to think in some sort of shorthand. This means the use of psychological concepts which we handle as if they were facts. Unfortunately the gap between cybernetics and psychology is a big one and an attempt to reconcile the two can only be conjectural. Nevertheless it may be useful if it reduces misunderstanding.

The analytical schools of psychopathology have used the concept of the unconscious mind, seen as a primitive organisation of thoughts operating by different rules from those of conscious thinking, and, by some, as containing in the lowest levels such things as racial memory. Out of this thinking comes the idea of conversion hysteria, an incompetent behavioural reaction occurring in certain people under certain conditions and necessarily involving unconscious mechanisms. However, the behaviour is not usually totally incompetent and it may, indeed, be highly efficient in removing an unpleasant problem. It follows, as night the day, that similar behaviour can result from perfectly ordinary conscious decisions. It is then known as malingering and is regarded as reprehensible, offensive and meriting punishment whereas such behaviour unconsciously produced would call for help, sympathy and understanding. The trouble is, it is impossible to distinguish between these two mechanisms in practice by anything other than prejudiced subjective decision. This difficulty is one of the reasons why the diagnosis of hysteria is increasingly in disrepute and why those who make it are suspected by those whose prejudices happen to give them an equal but opposite bias.

The patients, if such they are, exist, so the concept cannot simply be removed, it must be replaced by something. At the least we can say that all patients have one thing in common, they have adopted the role of sick people, perhaps because a femur has not been able to withstand a deforming force and has fractured or perhaps because the mind has been similarly inadequate. We can leave open the question of whether the man wanted to have his leg broken or whether he wanted to suffer a psychological breakdown-either of which may remove him from the battle scene.

The real reason for fruitless attempts to distinguish between hysteria and malingering may be because, even in the absence of a physical lesion', most doctors " tend to oscillate uneasily between two alternative attitudes-either there is nothing wrong with the 
patient, or he is psychiatrically ill " (Kendall 1974). This concept of the sick role could help in management, as well as diagnosis, in that it demonstrates that treatment must aim at removing the stress by means compatible with the realities of the situation but must minimise inessential advantages of the status of sick person and increase those of the restoration of health. The diagnosis of malingering with its concomitant rejection and hostility which deprive the coward of the friendly support he so desperately needs is not only impossible but incompetent and possibly even dangerous.

Breakdown under battle stress has its origins long before the battle, in the days when habits of behaviour are being formed, that is, in childhood. When we suffer the common minor illnesses of childhood we do not have to go to school and we are given extra supplies of sweet drinks with increased amounts of maternal care and affection. The price, apart from the illness itself, is small because we merely have to keep warm in bed. Similarly in adult life, adopting the sick role earns many benefits including indulgence from the family, treatment from doctors, care from nurses, patience from creditors and employers and payments in cash from the state, all at the relatively small price of restricted activities. Moreover, the milder the illness the smaller the price and the greater the relative profit. It is easy to believe that, to those who are often ill or whose schooling or day to day life is traumatic or whose family offers attention and affection only during illness, the attractions of the sick role in seeking comfort and avoiding pain can be very great. If we put a man trained in this role in a position of intolerable stress and with no other means of escape, not even the luxury of wounds or exogenous illness, he may well lapse into his comfort habit and simulate illness. The illness he simulates is likely to be one which those who care for him medically are willing to accept but cannot understand or determine accurately.

Turning to an attempt to bridge the gap between psychology and physiology from the other side one can also see the stresses of battle as sensory inputs which are apperceived i.e., viewed in the light of previous experiences. They form a pattern of powerful cortical stimulation. This fore-brain stimulation, in turn, has an influence on the hypothalamus, where visceral and somatic reaction patterns are integrated, and on the limbic system and reticular substance (Raisman 1966, Nauta 1963, Papez 1937). Activation leads to the secretion of corticotrophin releasing factor (C.R.F.) into the hypophysial portal system which stimulates the secretion of corticotrophin (ACTH) by the basophil cells of the anterior pituitary gland. Thus adrenocortical hormone secretion, principally of cortisol, is stimulated by a chain of events which multiplies effects at each step from cortex to hypothalamus to pituitary to adrenal and on to target organs. Increased secretion has three relevant effects, that is, acute and chronic physiological changes and negative feed-back effects on the pituitary through hypothalamic corticotrophin release inhibiting factor (C.R.I.F.). The acute effects include mobilisation of amino-acids (Christensen 1961), increased gluconeogenesis, increased extra-cellular volume and diuresis, sodium retention, sensitization of arterioles to pressor effects of catecholamines (Brodie et al 1966) and maintenance of muscular strength (Forsham 1962, Sayers and Travis 1970). More prolonged exposure reduces resistance to insulin, wasting of muscles, bones and skin and mobilisation of fat (Carpenter, Strauss and Burney 1973). On the other hand, deficiency produces inability to concentrate, drowsiness, restlessness, insomnia, irritability, apprehension and disturbed sleep (Addison 1855) with hypotension, muscular weakness, hypoglycaemia and sodium depletion. 
At the same time hypothalamic stimulation also affects the secretion of thyroxine, growth hormone, glucagon, follicle stimulating hormone, luteinising hormone, and most importantly, catecholamine production by the adrenal medulla. Noradrenaline in the circulation derives only partly from the adrenal medulla but the adrenaline comes almost entirely from it (Euler, Franksson and Hellstrom 1954). These substances act in concert with adrenocortical hormones in the adaptation to stress (Brodie et al 1966, amonsgt others). They act as the fine adjustment, from minute to minute, of a system which is generally set for catabolism on the one hand or anabolism on the other by the pituitary-adrenal axis and other hormone secretions. Adrenergic effects on heart and circulation and on respiratory digestive and nervous systems are too well known to require description. It has been suggested (Frohlich, Dunstan and Page 1966) that there can be a hyper-dynamic beta-adrenergic circulatory state which can produce an anxiety state without the requirement for dominant psychological factors and that this condition can be treated effectively by propanalol or practolol (Bonn, Turner and Hicks 1972). Not only do psychological stimuli alter the somatic setting but physiological arousal affects the perception and emotional reactions to sensory stimuli.

There is considerable evidence that psychological stress actually does produce raised plasma corticosteroid levels (Mason 1959, Davis et al 1962, Fishman et al 1962, Bridges 1974). This includes the demonstration of raised cortisol levels among military leaders in imminent danger of attack (Bourne, Rose and Manson 1968). To summarize, it would seem that the overall effect on the soldier is that alertness and physiological responsiveness to threatening stimuli increase progressively until the somatic ability to effect aggressive or defensive responses is maximal. This is normal and fully compatible with the fear experienced and objectively demonstrated in normal people exposed to battle. It is also compatible with a predilection to take up fear-provoking activities like free-falling parachuting which might be looked upon as addictive activities in which the stimulants obtained are endogenous.

Let us suppose however, that the exogenous stimuli are so excessive in amount, type or duration that the organism becomes flooded or that it is already set to be overstimulated as suggested by Frohlich, Dunstan and Page (1966). Then the responses will be excessive and incompetent and the person will present with inappropriate adrenergic responses i.e., startle reactions, dilated pupils, tachycardia, hypertension, muscular hypertonus and even inappropriate complex behaviour such as panic-stricken running or effective paralysis due to inability to select from a welter of excessive responses. These reactions add up to anxiety with or without panic.

Teleologically, it is tempting to argue that when excessive stimulation resulting in excessive secretion of corticosteroids and catecholamines is prolonged "exhaustion" would supervene to correct the balance and produce reversal of effects. In fact, unfortunately, our knowledge of the complex relationships between emotions and adrenal functions are limited and such a hypothesis cannot be relied upon as anything more than an intellectual tool. If accepted, however, it would suggest that the recognised clinical conditions of battle exhaustion and depression, which have usually been regarded as distinct entities may each depend on the relative severity of deficiency of catecholamines on the one hand or cortisol on the other. It is a widely popular hypothesis that depression, and possibly even unhappiness, involves a depletion of mid-brain mono-amines, a 
concept which underlies the use of both mono-amine oxidase inhibitors (Kline, Loomer and Saunders 1957) and tricyclic antidepressants (Ban 1969) in the treatment of spontaneous depression. The acute depression of battle may result from a similar process, with the important differences that the integration of the organism is normal and that recovery is spontaneous on removal of the only " precipitating" cause. If the pituitary/ adrenal axis fails the effective cortisol level is reduced and there is a corresponding fall in blood sugar, cardiac output, muscular strength etc. and exhaustion results. Such a syndrome would be "neurasthenic" only in its causation, both its mechanisms and its manifestations being predominantly physical.

Both of these modern views of psychiatric illness seem to integrate well with the pragmatic rules for the management of battle casualties, and would be highly questionable if they did not, that is to say:-

(a) Treatment should be "forward" and be based on the tacit assumption that early recovery and return to duty will occur. From the physiological point of view we are dealing with a naturally reversible decompensation and, psychologically, reluctance to give advantage to the sick role is, in itself, therapeutic.

(b) Psychiatrists are not necessary for the treatment of any but resistant cases. Biochemically, the developed condition would not seem likely to be responsive to psychotherapy and psychologically there is a danger that the availability of a psychiatrist may foster the adoption of the sick role by those near the limits of endurance:

(c) Treatment should be brief and simple, involving a sympathetic ear in relatively restful surroundings and the minimum sedation compatible with mobility needs, that is removal from stress, with understanding but with minimal sustained secondary advantage from the sick role itself. On no account must the casualty be dealt with harshly or in a derogatory way.

(d) Evacuation of psychiatric casualties to base is rarely followed by return to full duty. The sick role has demonstrated its effectiveness and will operate again more and more easily. For that matter, the same principle applies to other casualties who tend to be more difficult to get back to full duty the farther they go in time or distance from battle.

These ideas might also provide some advance in helping to understand the nature of psychiatric casualties and, more important in practical terms, in helping us to accept what they really are. The gap between brain and mind is by no means closed, of course, and the two approaches described refer predominantly to different groups of people. Perhaps the overlap is a little smaller and it is important to emphasise in any case, that the gap between "normal " and " abnormal" is well and truly closed, certainly if we are considering the very high proportion of people likely to break down under really serious mass casualty situations. The potential to become a psychiatric battle casualty is a common, if not universal, feature of the human condition.

\section{REFERENCES}

Addison, T. (1855). On the Constitutional and Local Effects of Disease of the Suprenal Capsules. Highley, London.

ARHENFELDT, R. H. (1968). Medical Services in War. Military Psychiatry. H.M.S.O. London.

BAN, T. A. (1969). Psychopharmacology. Williams \& Wilkins, Baltimore. P.210-286.

Belas, R. J. (1973). J. roy. Army med. Cps. 119, 3 
Bonn, J. A., Turner, P. and Hicks, D. C. (1972). Lancet i, 814.

Bourne, P. G., Rose, R. M. and Mason, J. W. (1968). Arch. gen. Psychiat. 19, 135.

BRIDGES, P. K. (1974). Biol. Psych. 8, 1.

Brodie, B. B., Davies, J. I., Hyme, S., Krishna, G. and Weis, B. (1966). Pharmacol. Rev. 18, 273.

Carpenter, W. T., Strauss, J. S. and Burney, W. E. (1973). In Psychiatric Complications of Medical Drugs. North Holl. Amsterdam.

Christenson, H. N. (1961). Metabolic Effects of Adrenal Hormones, Ciba. Little, Brown. Boston.

Davis, J., Murrill, R., Fawcett, L., Upton, V., Bondy, P. K. and Spiro, H. M. (1962). J. psychosom. Res. 6, 83.

Euler, U. S. Von, Franksson, C. and Hellstrom, J. (1954). Acta physiol. scand. 31, 1.

Fishman, J. R., Jamburg, D. A., Handlon, J. H., Mason, J. W. and Sachar, E. (1962). Arch. gen. Psychiat. 6, 271.

Forsham, P. H. (1962). The Adrenals. In R. H. Williams (Ed.) Textbook of Endocrinology. Saunders. Philadelphia.

Frohlich, E. D., Dunstan, H. P. and Page, I. H. (1966). Arch. intern. Med. 117, 614.

Kendeli, R. E. (1974). Medicine (Baltimore) 30, 1780.

KLINe, N. S., Loomer, H. P. and Saunders, J. C. (1957). In Remmen, E. et al. Psychochemotherapy (1962). Western Medical Publications, Los Angeles.

Mason, J. W. (1959). Recent Progr. Hormone Res. 15, 345.

NaUta, W. J. W. (1963). Advances in Neuroendocrinilogy. Nalbandor (Ed.). University of Illinois. Illinois.

PAPEZ, J. W. (1937). Arch. Neurol. Psychiat. (Chic.) 38, 725.

RAISMAN, G. (1966). Brit. med. Bull. 22, 197.

SAYERS, G. and Travis, R. H. (1970). In Goodman and Gilman. The Pharmacological Basis of Therapeutics. MacMillan. New York.

\section{Consultant Emeritus to the Army}

Dr. Davis Evan Bedford, C.B.E., M.D., F.R.C.P., former Chairman of the Council of the British Heart Foundation and co-editor of the British Heart Journal, has become a Consultant Emeritus to the Army.

The Army has six consultants emeriti. The others are Sir John Richardson, Sir Stewart Duke-Elder, Mr. Myles Formby, Lord Porritt and Sir Terence Ward.

\section{Queen's Honorary Physician}

Colonel J. B. Bridges, T.D., M.D., M.B., Ch.B., R.A.M.C. (T.A.V.R.), was appointed Honorary Physician to The Queen as from 1 April 1976, in succession to Colonel R. Price, T.D., M.B., Ch.B., R.A.M.C. (T.A.V.R.).

Fellow of the Royal College of Surgeons

Colonel Robert Ollerenshaw, E.R.D., T.D., D.L., M.A., B.M., D.M.R.D., was admitted F.R.C.S. without examination in July 1975.

We apologise for this belated entry.

\section{ACADEMIC ACHIEVEMENTS}

F.R.C.R.

Major C. N. O’N. DigGes, M.A., M.B., B.Ch., B.A.o., R.A.M.C.

M.R.C.O.G.

Major J. F. Depasquale, M.D. D.obst.R.C.o.G., B.Pharm. R.A.M.C.

D.C.H.

Captain M. F. Wigfield, M.B., B.S., R.A.M.C. 